Volume 8, No.1, January - February 2019

International Journal of Advanced Trends in Computer Science and Engineering

Available Online at http://www.warse.org/IJATCSE/static/pdf/file/ijatcse10812019.pdf

https://doi.org/10.30534/ijatcse/2019/10812019

\title{
Numerical Performance Evaluation of Savonius Rotors by Flow-driven and Sliding-mesh Approaches
}

\author{
A. Zakaria ${ }^{1}$, M. S. N. Ibrahim \\ ${ }^{1}$ Universiti Kuala Lumpur Malaysia Italy Design Institute, Malaysia, dzakaria@unikl.edu.my
}

\begin{abstract}
Two different techniques for simulating aerodynamic performance of an isolated and multiple helical Savonius rotors with $180^{\circ}$ twist angle are compared in this study. Designed to operate at a wind speed range of between 2 to 5 $\mathrm{m} / \mathrm{s}$, this drag-type vertical axis wind turbine was evaluated by using commercial Computational Fluid Dynamics (CFD) code. The first technique is based on the tip speed ratio (TSR) incorporating a sliding mesh interface to estimate its optimal power coefficient. On the other hand, a flow-driven concept is adopted in the second technique where a rigid body dynamics (RBD) parameters of the rotor are defined. Common parameters applied to both models include grid size, domain size, turbulence models and the boundary conditions. In general, both techniques yielded the same results in terms of power curves with respect to wind velocity for the isolated and multiple rotor arrangements. This, in fact, is in close agreement with the published data. However, the flow-driven approach is found to have advantages over the conventional sliding method. This is particularly true in cases where a comparison of different rotor blade materials is required. In addition, it can readily accommodate for known external loads acting of the rotor such as resistive torque of its generator.
\end{abstract}

Key words: CFD, Flow-driven, Savonius, Sliding-mesh, Wind Farm.

\section{INTRODUCTION}

In choosing the appropriate technique for simulating airflow around a vertical axis wind turbine (VAWT), accuracy and computational cost are always the main criteria to be considered. The most popular and widely used technique is known as a sliding mesh (SM) approach. Here the rotating zone and stationary zone separating by an interface are defined within the computational domain. With the surface of a rotor blade of interest located inside the rotating zone, a known angular velocity computed by the tip speed ratio (TSR) relationship is imposed on the rotating zone. Repeating this transient analysis procedure for different angular velocities will enable power coefficient or $\mathrm{C}_{\mathrm{p}}$ to be determined at different TSR. The highest $\mathrm{C}_{\mathrm{p}}$ attained is considered optimum. This approach is reported to be more reliable than the steady state or frozen rotor (MRF) approach although the computing cost for the latter is much less than the former [1]. However, the MRF method is normally employed prior to SM analysis.

Unlike turbomachinery equipment such as pumps where its operating angular velocity is known hence it is quite natural to adopt the sliding mesh approach. However, it is arguable that for devices such as wind or hydro-kinetic turbine which depend largely on fluid velocity for its optimal operation, a flow-driven approach is more appropriate [2]. Instead of angular velocity defined, in the flow-driven (FD) approach the moment of inertia of the turbine is added. Hence the torque or moment can be calculated by knowing the net force acting on the rotor blade. This method allows easy comparison with actual experimentation results. And naturally, it is best suited for an analysis involving different types of blade materials.

Flow over the turbine is usually turbulent and therefore choosing the right turbulence model is important in order to obtain an acceptable, reliable and accurate results. In general, the selection of an appropriate turbulence model is dependent on the Reynolds number. Again computing cost is another important factor to be considered. In general, selection of the turbulence model is depending on the Reynolds number [3].

Many research thus far has focused on the rather high wind speed of more than $6 \mathrm{~m} / \mathrm{s}$ in combination with complex turbulence model. In this study, a helical Savonius rotor with $180^{\circ}$ twist angle is used as a case study in an attempt to understand the flow around the turbine at a wind speed range of 2 to $5 \mathrm{~m} / \mathrm{s}$. Recent studies also show a great improvement in power efficiency when multiple turbines are arranged in a specific configuration. Two turbines arranged in oblique configuration at a 60-degree angle downstream to a second turbine gives the highest power efficiency. Similarly, improved overall performance is obtained for a cluster of three turbines with two turbines on upstream and one turbine at downstream [4].

The main objective of this study was to evaluate the performances of a single and multiple helical Savonius rotors by using the flow-driven (FD) approach and to compare the results with the conventional sliding mesh (SM) model. 


\section{CFD SIMULATIONS}

\subsection{Description of the Turbine Rotor}

The helical Savonius of $1 \mathrm{~m}$ high and $0.5 \mathrm{~m}$ diameter with $180^{\circ}$ twist angle as shown in Figure 1 is used in this study. Overlap ratio, e/d of 0.242 is used for the rotor design. The rotor is designed to rotate in an anti-clockwise direction.
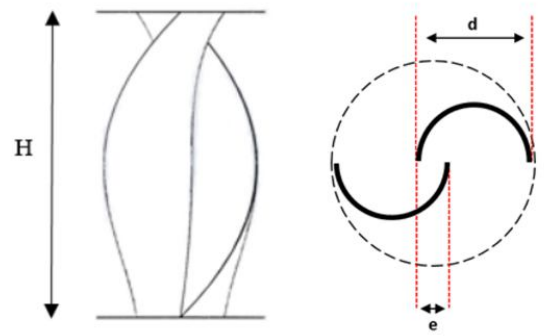

Figure 1: Helical Savonius rotor with $180^{\circ}$ twist angle

\subsection{Computational Domain and Boundary Condition}

Initially, a standalone or isolated Savonius rotor was first analyzed. A 3D computational domain consists of a rectangular prism fixed domain with a dimension of Lz, Ly and Lx "to be published" [5] and a cylinder defining a rotating domain is placed in the fixed domain as shown in Figure 2 where $\mathrm{D}$ is the rotor diameter. The interface was set between the rotating domain and fixed domain. Slip and non-slip walls are defined for the domain outer surfaces and the rotor surface respectively. The inflow velocity, $\mathrm{V}$ for $\mathrm{SM}$ model was $5 \mathrm{~m} / \mathrm{s}$ while a range of $2-5 \mathrm{~m} / \mathrm{s}$ was set to the FD. A commercial CFD code called AcuSolve running on a 16-core machine was used for both transient analyses by sliding mesh and flow-driven approaches. Spalart-Allmaras turbulence model was applied to both techniques. The sensitivity analysis was not considered.

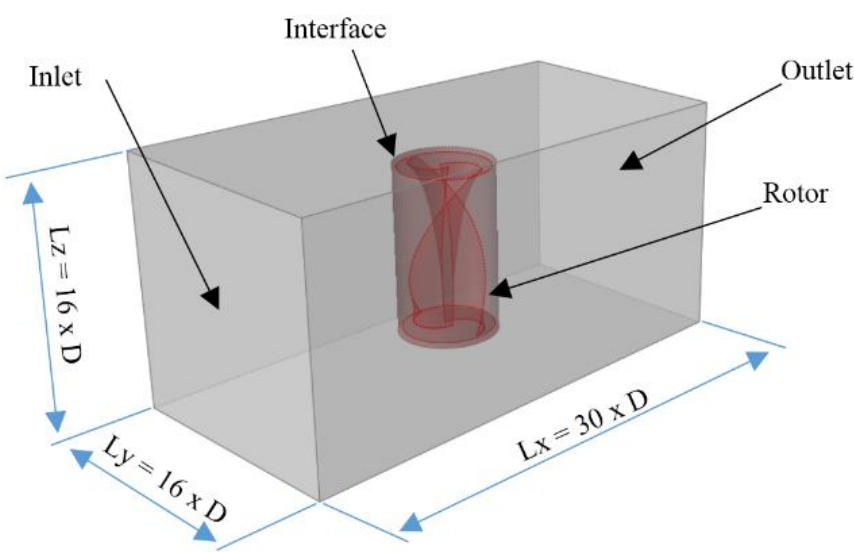

Figure 2: 3D Computational domain and boundary conditions

\subsection{Multiple Rotors Arrangements}

Multiple wind turbine configurations were analyzed to allow for a fair comparison between SM and FD approaches. The configurations implemented by Shaheen et al [4] are adopted for this analysis. The oblique arrangement comprising two rotors was set with $\alpha=$ negative 60 -degree from the horizontal line at gap distance $S$ of 1D. Likewise, the cluster of three turbines is modeled at $\mathrm{S}=0.2 \mathrm{D}$ [4]. Both turbine arrangements are illustrated in Figure 3 (a) and (b) respectively.
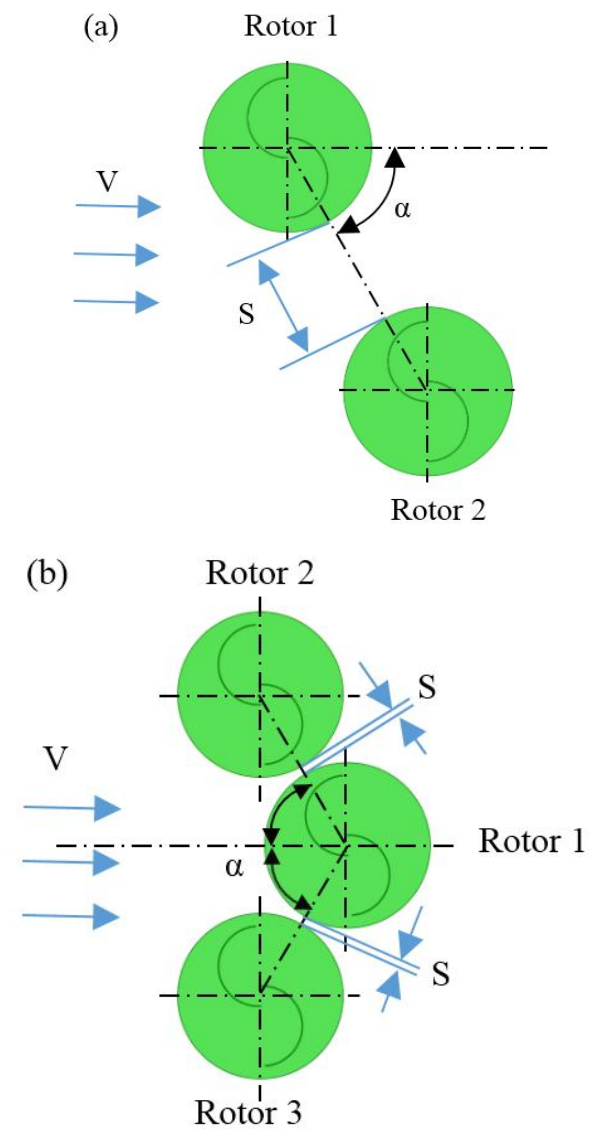

Figure 3: 3D Computational domain and boundary conditions [4]

\section{RESULT AND DISCUSSIONS}

The performance of Savonius rotor can be described by power coefficient relation, $\mathrm{C}_{\mathrm{p}}$. The $\mathrm{C}_{\mathrm{p}}$ is the ratio of actual power generated by the rotor to the theoretically available power at a wind speed of interest. $C_{p}$ at various wind speed was calculated according to the following equations:

$\mathrm{C}_{\mathrm{p}}=\mathrm{P}_{\mathrm{act}} / \mathrm{P}_{\mathrm{th}}$

$\mathrm{P}_{\mathrm{act}}=\mathrm{T} \omega$

$\mathrm{P}_{\mathrm{th}}=0.5 \rho \mathrm{AV}^{3}$ 
Where T is a torque generated by the rotor (N.m), $\omega$ is stable angular velocity, $(\mathrm{rad} / \mathrm{sec}), \rho$ is air density $\left(1.225 \mathrm{~kg} / \mathrm{m}^{3}\right), \mathrm{A}$ is swept area of the rotor $\left(\mathrm{H} \times \mathrm{D}, \mathrm{m}^{2}\right), \mathrm{V}$ is inflow velocity $(\mathrm{m} / \mathrm{s})$.

Note that the actual power $\left(\mathrm{P}_{\mathrm{act}}\right)$ generated by each rotor is computed from simulated torque and rotational speed generated by numerical analysis. However, in the case SM method, the angular speed is obtained from the tip speed ratio (TSR) relation as shown in (4) where R is rotor radius.

$\mathrm{TSR}=\omega \mathrm{R} / \mathrm{V}$

\subsection{Isolated Rotor Analysis}

The power curve for the isolated helical Savonius generated at different TSR by SM technique is shown in Figure 4 (a). Figure 4 (b) shows the power coefficient for respective wind speed obtained by FD technique. Please note that the power curve showed in Figure 4 (a) is for a wind speed of $5 \mathrm{~m} / \mathrm{s}$. TSR for FD generated is represented by the orange line in Figure 4 (b).
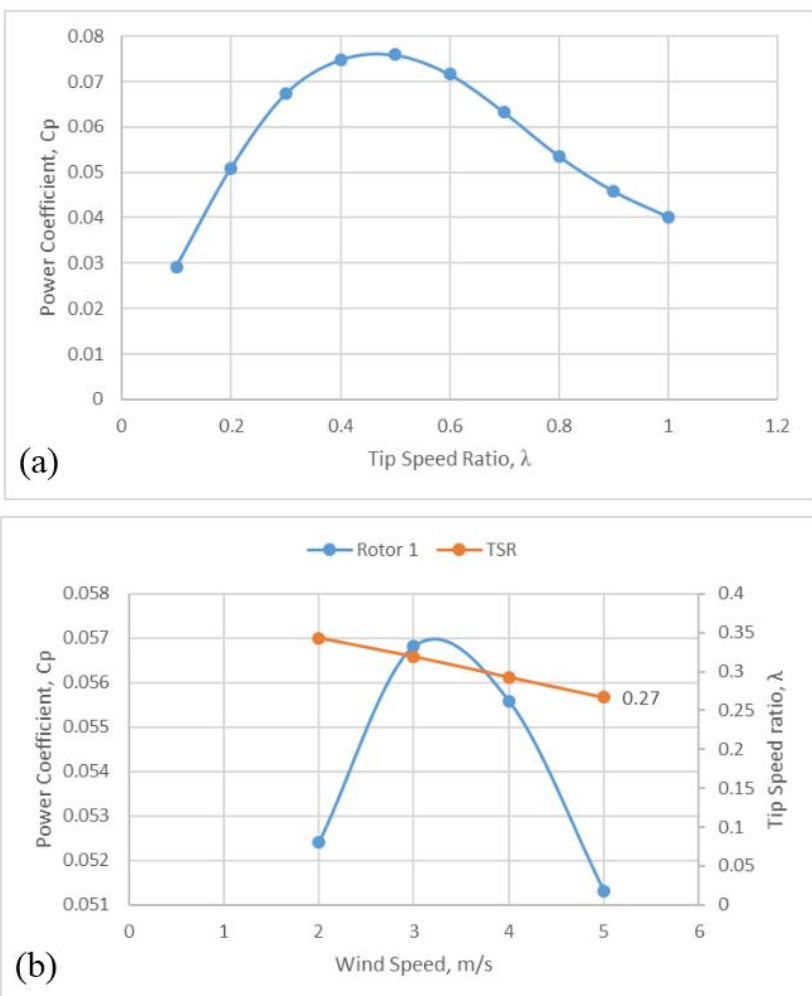

Figure 4: Power curve by SM (b): Rotor performance at different wind speed by FD

SM predicted the optimum $\mathrm{Cp}$ of 0.076 to occur at $\mathrm{TSR}=0.5$ whereas in the case of FD the optimal Cp of 0.051 to occur at TSR $=0.27$. Hence the error between these two methods is about $50 \%$. This error was expected since the sensitivity analysis was ignored.

\subsection{Oblique Rotor Configurations Analysis}

As shown in Figure 5, both techniques predicted the rotor 2 in downstream position to have a higher power efficiency compared to rotor 1 . The average $C_{p}$ appears to improve when compared to an isolated rotor. This is an agreement with [4].
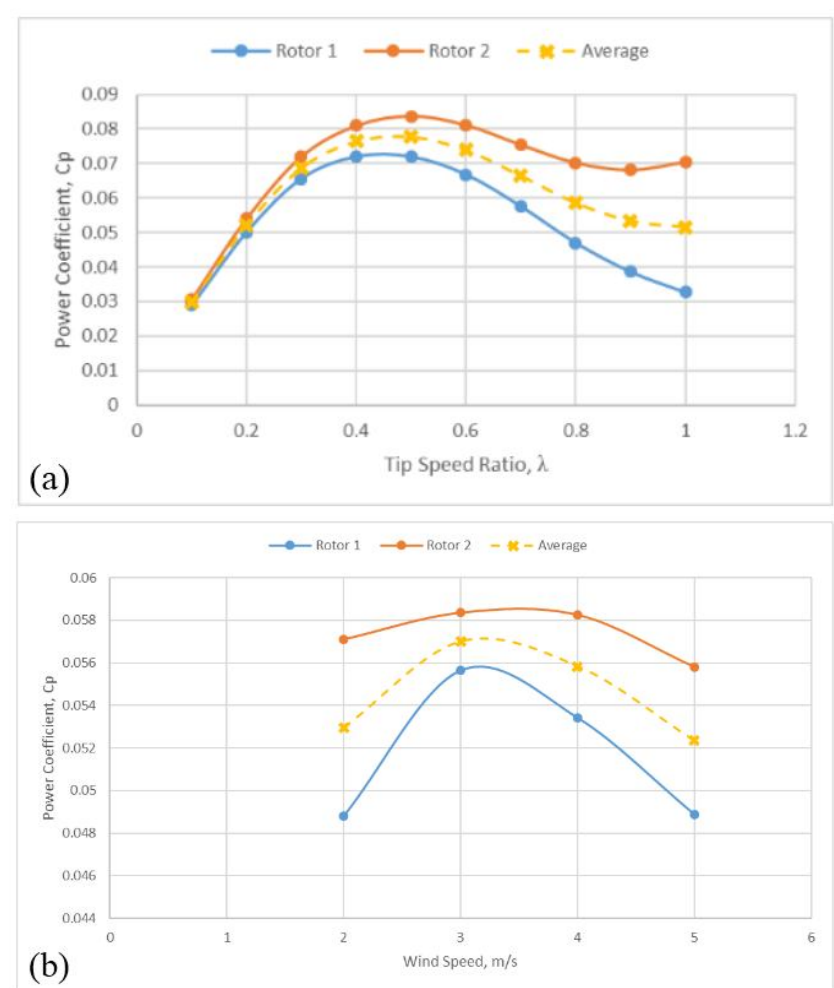

Figure 5: (a): Oblique configuration power curve by SM (a) and FD (b)

Although increasing and decreasing of $\mathrm{C}_{\mathrm{p}}$ is observed in both power curves, the FD method gives a better picture of the range of wind speeds at which maximum $\mathrm{C}_{\mathrm{p}}$ is achieved. In this case, the speed range is between 3 and $4 \mathrm{~m} / \mathrm{s}$.

\subsection{Cluster Arrangement Analysis}

The power curves obtained from both techniques are very much similar to the oblique configuration described above. Individual rotor performance of the three rotors: rotor 1, rotor 2 and rotor 3 are shown in Figure 6 (a) and (b).

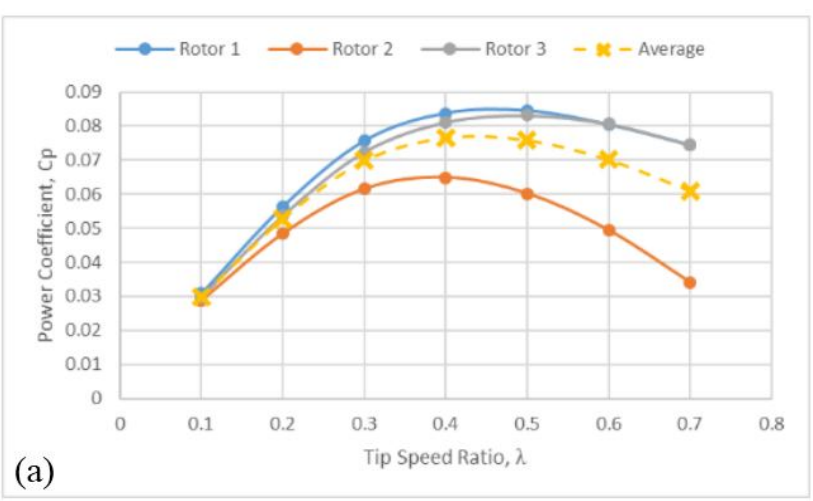


A. Zakaria et al., International Journal of Advanced Trends in Computer Science and Engineering, 8(1), January - February 2019,57 - 61

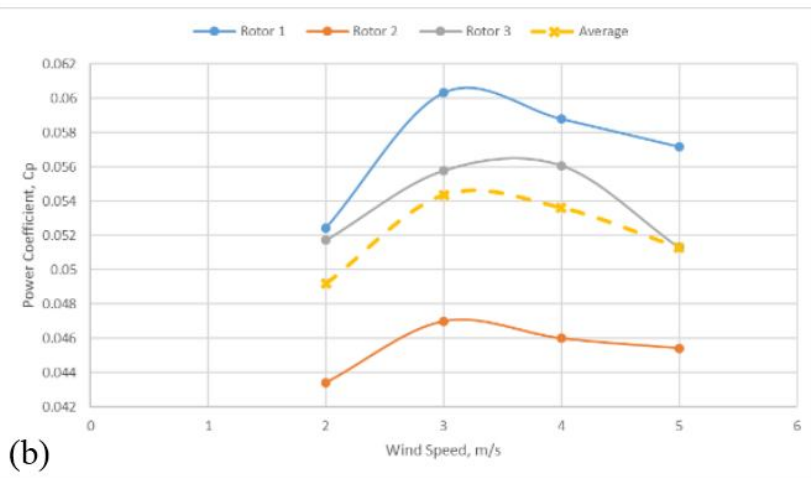

Figure 6: (a) \& (b): Rotor performance predicted by SM and FD techniques respectively

Rotor 1 shows an improved power coefficient of 0.08 and 0.06 for SM and FD method respectively. This is followed by rotor 2 and 3. Similar results are also obtained by [4] for cluster turbines analysis.

\subsection{Angular Velocity Prediction}

Figure 7 shows how an individual rotor starts to rotate after the zero-time step and accelerate to a steady state condition. SM technique, however, depicts three rotors to have a stable angular velocity at the start till the end of the simulation.

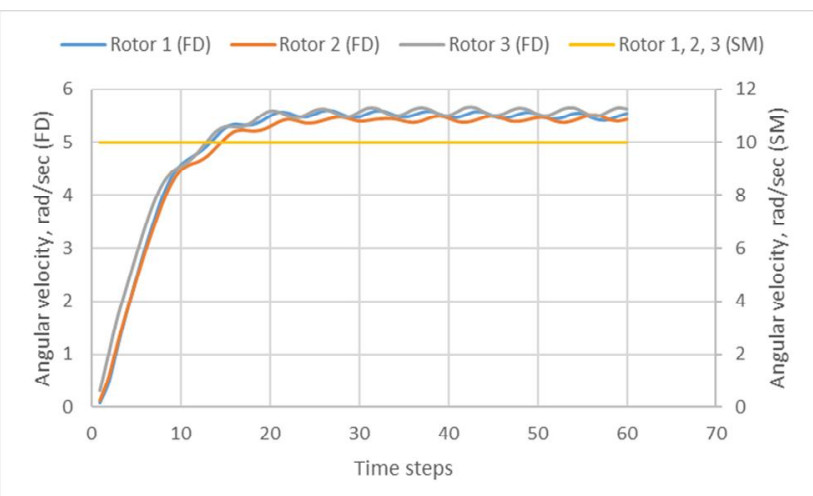

Figure 7: Angular velocity behavior predicted by SM and FD (Cluster configuration, $\mathrm{V}=5 \mathrm{~m} / \mathrm{s}$ )

Hence one can expect that computational time for FD method is much longer compared to SM since a longer time step is needed for its simulation. Unfortunately, though a shorter time step is required for the SM method, this is, however, outweighed by the fact that the same simulation has to be repeated for other TSR.

To further understand the flow around multiple turbines, velocity contours of the oblique turbine configurations generated by both SM and FD are shown in Figure 8. Figure 8 (a) shows the rotors are in a different position at the instantaneous time step using the FD approach. When compared to the vortices generated by the SM method, both look identical. (a)
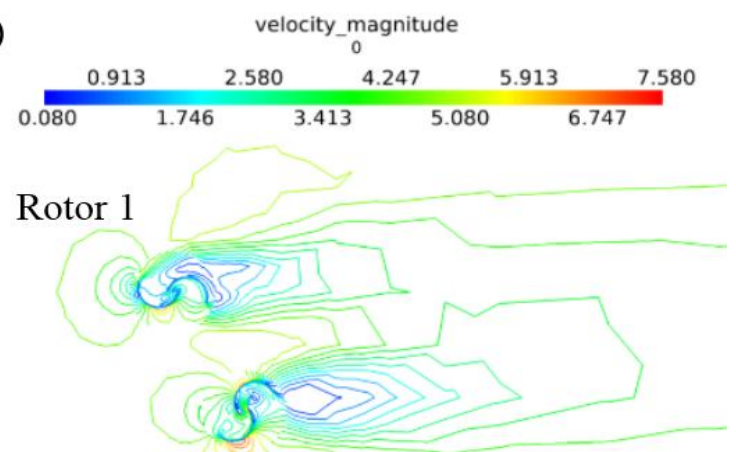

Rotor 2

(b)
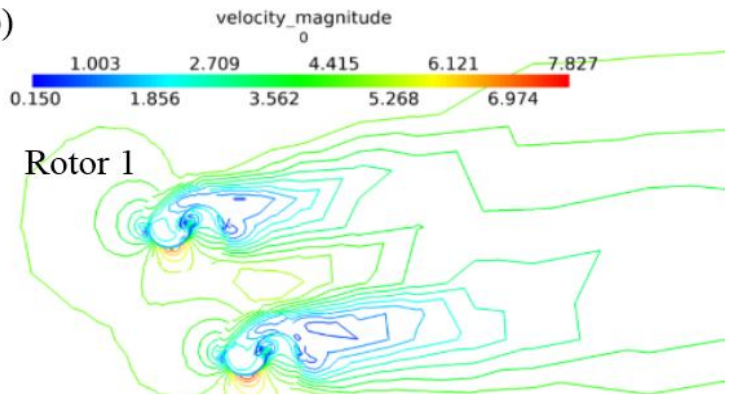

Rotor 2

Figure 8: Velocity contour for oblique configuration analysis for both techniques

The main advantage of FD technique is that the resulted angular velocity is dependent on the incoming wind speed. Therefore, in the case of multiple turbines simulation, the angular velocity for each turbine is different to reflect the real experimentation data. In the case SM, different individual turbine performance is measured by the torque generated.

\section{CONCLUSION}

In many cases, the results obtained by the sliding mesh method and the flow-driven method are the same both in terms of rotor performance such as $\mathrm{C}_{\mathrm{p}}$ as a function of wind velocity. However, the flow-driven method can readily be validated with the actual wind tunnel test results. Specifically, the advantages of the FD method over the SD method can be summarized as in Table 1.

Table 1: FD vs SM method

\begin{tabular}{|l|c|c|}
\hline & $\begin{array}{c}\text { Flow-driven } \\
\text { method }\end{array}$ & $\begin{array}{c}\text { Sliding mesh } \\
\text { method }\end{array}$ \\
\hline 1. Computational cost & High & High \\
\hline $\begin{array}{l}\text { 2. Application of } \\
\text { external load }\end{array}$ & Yes & No \\
\hline $\begin{array}{l}\text { 3. Variation in rotor } \\
\text { materials }\end{array}$ & Yes & No \\
\hline $\begin{array}{l}\text { 4. Rotor rotational } \\
\text { speed }\end{array}$ & $\begin{array}{c}\text { Airflow velocity } \\
\text { dependent }\end{array}$ & Based on TSR \\
\hline $\begin{array}{l}\text { 5. Validation with } \\
\text { wind tunnel test }\end{array}$ & Direct & Indirect \\
\hline
\end{tabular}




\section{ACKNOWLEDGEMENT}

The authors would like to acknowledge the Malaysian Electricity Supply Industries Trust Account (AAIBE) through the Ministry of Energy, Science, Technology, Environment \& Climate Change (MESTECC) for funding this research.

\section{REFERENCES}

1. M. Tabib, M. S. Siddiqui, A. Rasheed, and T. Kvamsdal. Industrial Scale Turbine and Associated Wake Development-Comparison of RANS based Actuator Line Vs Sliding Mesh Interface Vs Multi-Reference Frame Method, Energy Procedia, vol. 137, pp. 487-496, 2017.

https://doi.org/10.1016/j.egypro.2017.10.377

2. T. Q. Le, K. Lee, J. Park, and J. H. Ko. Flow-driven Rotor Simulations of Vertical Axis Tidal Turbines: A Comparison of Helical and Straight Blades, International Journal of Naval Architecture and Ocean Engineering, vol. 6, no. 2, 99. 257-268, 2014.

3. K. Rogowski and R. Maroński. CFD computational of the Savonius rotor, Journal of Theoretical and Applied Mechanics, vol. 53, no. 1, pp. 37-45, 2015. https://doi.org/10.15632/jtam-pl.53.1.37

4. M. Shaheen, M. El-Sayed, and S. Abdallah. Numerical study of two-bucket Savonius wind turbine clusters, Journal of Wind Engineering and Industrial Aerodynamics, vo. 137, pp. 78-89, 2015.

https://doi.org/10.1016/j.jweia.2014.12.002

5. A. Zakaria and M. S. N. Ibrahim. Time step sensitivity analysis of flow-driven Savonius rotor, 4th International Conference on Mechanical, Manufacturing and Process Engineering, (ICMMPE' 18), Malaysia, (2018). 